\title{
Role of Acquired Von Willebrand Syndrome in Patients Treated Using Impella RP® Devices: A Retrospective Cohort Study
}

Mehmet Oezkur ( $\square$ m.oezkur@gmail.com )

University Medical Center of the Johannes Gutenberg University Mainz

\section{Sara Reda}

University Hospital Bonn

Heiko Rühl

University Hospital Bonn

Nils Theuerkauf

University Hospital Bonn

Stefan Kreyer

University Hospital Bonn

\section{Daniel Duerr}

University Medical Center of the Johannes Gutenberg University Mainz

\section{Efstratios Charitos}

University Hospital Bonn

\section{Miriam Silaschi}

University Hospital Bonn

\section{Marta Medina}

University Hospital Bonn

\section{Sebastian Zimmer}

University Hospital Bonn

\section{Christian Putensen}

University Hospital Bonn

\section{Hendrik Treede}

University Medical Center of the Johannes Gutenberg University Mainz

\section{Research Article}

Keywords: Impella ${ }^{\circledR}$, axial flow pump, anticoagulation, heparin, acquired von Willebrand syndrome

Posted Date: July 29th, 2021

DOI: https://doi.org/10.21203/rs.3.rs-751063/v1 
License: (c) (i) This work is licensed under a Creative Commons Attribution 4.0 International License. Read Full License 


\section{Abstract}

Background: Axial flow pumps are standard treatment in cases of cardiogenic shock and high-risk interventions in cardiology and cardiac surgery, although the optimal anticoagulation strategy remains unclear. We evaluated whether laboratory findings could predict bleeding complications and acquired von Willebrand syndrome (avWS) among patients who were treated using axial flow pumps.

Methods and Results: We retrospectively evaluated 60 consecutive patients who received Impella ${ }^{\circledR}$ devices (Impella ${ }^{\circledR}$ RP: $n=20$, Impella ${ }^{\circledR}$ CP/5.0: n=40; Abiomed Inc., Danvers, USA) between January 2019 and December 2020. Thirty-two patients (53.3\%) experienced major or fatal bleeding complications (Bleeding Academic Research Consortium score of $>3$ ) despite intravenous heparin being used to maintain normal activated partial thromboplastin times (40-50 s). Extensive testing was performed for 28 patients with bleeding complications (87.5\%). Relative to patients with left ventricular support, patients with right ventricular support were less likely to develop avWS ( $87.5 \%$ vs. $58.8 \%, p=0.035)$. Bleeding was significantly associated with avWS (odds ratio [OR]: $20.8,95 \%$ confidence interval [CI]: $3.3-$ 128.5; $\mathrm{p}=0.001$ ) and treatment duration (OR: $1.3,95 \% \mathrm{Cl}: 1.09-1.55 ; \mathrm{p}=0.003)$. Patients with avWS had longer Impella ${ }^{\circledR}$ treatment than patients without avWS ( 2 days [ $1-4.7$ days] vs. 7.3 days [3.2-13.0 days]).

Conclusions: Anticoagulation monitoring based on aPTT was not sufficient to prevent bleeding complications during axial flow pump support. A more targeted anticoagulation monitoring is needed for patients who receive Impella ${ }^{\circledR}$ devices.

\section{Introduction}

Treatment of cardiogenic shock remains a clinical challenge despite recent innovations in the field of mechanical circulatory support (MCS). Impella ${ }^{\circledR}$ devices (Abiomed Inc., Danvers, MA) were recently added to the MCS arsenal, alongside extracorporeal membrane oxygenation (ECMO), intra-aortic balloon pump, and the TandemHeart ${ }^{\circledR}$. Some studies have identified strategies for successfully treating cardiogenic shock, especially the combination of an Impella ${ }^{\circledR}$ device with ECMO ("ECMELLA"). ${ }^{1-5}$ Although other contemporary studies have indicated that use of the Impella ${ }^{\circledR} 2.5 / \mathrm{CP}$ devices is associated with adverse events and potentially higher mortality rates. ${ }^{6,7}$ Data regarding vascular and bleeding complications in patients with Impella 5.0/5.5/RP or the combination therapy of Impella and ECMO are missing. Life-threatening severe bleeding may affect the ability to deliver further successful treatment. ${ }^{6,7}$ Peripheral bleeding, including access site bleeding, has also been discussed as a possible cause of increased mortality. However, there are no prospective studies that have specifically considered these complications.

Bleeding complications in patients who receive permanent or temporary MCS devices are associated with a risk of acquired von Willebrand syndrome (avWS) ${ }^{8-15}$ The von Willebrand factor (vWF) is a multimeric protein and the highest molecular weight multimers play a major role in primary hemostasis by binding to 
clot-associated collagen and platelet glycoprotein receptors, which helps seal the injured vascular endothelium. Furthermore, vWF is stored in the Weibel-Palade bodies of the endothelium as well as in platelet alpha granules. Therefore, vWF can be considered a plasma indicator of endothelial dysfunction and increased vascular vulnerability. Large vWF multimers are cleaved by the ADAMTS13 metalloprotease, especially under high shear stress conditions that promote the development of avWS. ${ }^{16}$ Impaired hemostasis related to VWF abnormalities may also be a risk factor for procedural bleeding.

A type of avWS was first described in patients who had received axial continuous flow pumps and this syndrome was reversed after device explantation. ${ }^{17-19}$ Federici et al. suggested that avWS could be identified based on a history of bleeding symptoms plus reduced vWF activity $(<50-65 \mathrm{IU} / \mathrm{dL}$ depending on blood type) and a reduced VWF activity-to-antigen ratio $(<0.7) .{ }^{20,21}$ Other researchers have also reported that a vWFn activity-to-antigen ratio of $>0.8$, in the normal range, and lower values to be indicative of vWF dysfunction 22.

However, critical illness and surgery can lead to a hypercoagulative state that is characterized by activation of coagulation and impairment of fibrinolysis. Thus, vWF activity and antigen levels are typically elevated in these settings, along with other coagulation factors, such as fibrinogen and coagulation factor VIII (FVIII), which can complicate the diagnosis of avWS. Moreover, there are limited data regarding the incidence of avWS and possible bleeding complications in patients who have received Impella ${ }^{\circledR}$ RP devices. Therefore, this study evaluated patients who received left or right ventricular Impella ${ }^{\circledR}$ support to determine whether the development of avWS was associated with bleeding complications. To the best of our knowledge, this is the largest single-center study to evaluate the relationship between avWS and bleeding complications in this setting.

\section{Methods}

The study protocol and data handling was approved by the Ethics Committee of the Medical Faculty and the data protection officer. An informed consent for the retrospective analysis of the data was obtained from all subjects. All methods were performed in accordance with the relevant guidelines and regulations for good clinical and good scientific practice. We evaluated adult patients ( $\geq 18$ years old) who had undergone elective or urgent cardiac surgery between January 2019 and December 2020. These procedures included thoracic aorta procedures and coronary artery bypass grafting with or without valve surgery (reconstruction or replacement). Patients were considered eligible if they had received an Impella ${ }^{\circledR} \mathrm{CP} / 5.0 / \mathrm{RP}$ device at any point during their hospitalization. The exclusion criteria were removal of the Impella ${ }^{\circledR}$ device and/or patient death during the first $24 \mathrm{~h}$ after implantation. All Impella ${ }^{\circledR} \mathrm{RP}$ devices had been implanted percutaneously via puncture of the femoral vein. All Impella ${ }^{\circledR} 5.0$ devices had been implanted surgically via the subclavian artery with a graft. All Impella ${ }^{\circledR}$ CP devices had been implanted via puncture of the femoral artery. Explantation was performed via venous compression alone (Impella ${ }^{\circledR}$ RP devices), using an 8-F Angio-Seal ${ }^{\circledR}$ device (Impella ${ }^{\circledR}$ CP devices), or surgically (Impella ${ }^{\circledR}$ 5.0 devices). 
The patients' medical records were searched to collect data regarding patient characteristics, comorbidities, surgical procedures, hemodynamic parameters, laboratory findings, medications, and transfusion of blood products (coagulation factors, fresh-frozen plasma, and platelet concentrates). The data were collected at admission/preoperatively; at the time of Impella ${ }^{\circledR}$ device implantation; at $24 \mathrm{~h}, 48$ $\mathrm{h}$, and $72 \mathrm{~h}$ after the implantation; and at 6 days after the implantation and/or at the explantation. All patients had received intravenous heparin anticoagulation to maintain a partial thromboplastin time (PTT) of 50-60 s. The primary endpoint was defined as the development of avWS, which was identified based on the ratio of VWF activity (VWF:Ac) to von Willebrand factor antigen (VWF:Ag), with a value of < 0.70 any time between the implantation and explantation indicating the development of avWS. ${ }^{22,23}$ The secondary endpoint was defined as major or fatal bleeding complications (Bleeding Academic Research Consortium [BARC] score of $>3$ ) during the treatment. ${ }^{8-15,24}$ Postoperative medical treatments in the intensive care unit were also evaluated.

Blood samples were centrifuged within $4 \mathrm{~h}$ and plasma samples were either immediately analyzed or stored at $-40^{\circ} \mathrm{C}$ until they were analyzed. Plasma concentrations of VWF:AG were measured using immunoturbidimetry (Innovance vWF:Ag assay; Siemens Healthcare Diagnostics, Eschborn, Germany). The vWF:Ac was determined using a vWF ristocetin cofactor assay (Innovance vWF:Ac assay; Siemens) ${ }^{25}$ Values for aPTT, antithrombin activity, thrombin clotting time, fibrinogen concentration (Clauss method), and plasma concentrations of D-dimer and coagulation factors II, V, VII, VIII, X, and XIII were determined using an automated coagulation analyzer (BCS XP or Atellica Coag 360, Siemens) and standard reagents. Reference ranges were established using blood test results from $\geq 100$ healthy blood donors. The reference ranges for blood type 0 were defined as $50-130 \%$ for VWF:Ag and $46-125 \%$ for VWF:Ac, while the reference ranges for non-O blood type were defined as $65-165 \%$ for VWF:Ag and 64$150 \%$ for vWF:Ac. Internal and external quality assurance was performed according to the German quality assurance guidelines for medical laboratory examinations.

\section{Statistical analysis}

Data were presented as number (percentage) or median (interquartile range). The characteristics and outcomes of the Impella ${ }^{\circledR}$ groups were compared using the $t$ test, Mann-Whitney $\mathrm{U}$ test, Kruskal-Wallis $\mathrm{H}$ test, $\chi^{2}$ test, or Fisher's exact test, as appropriate. Univariate regression analysis was performed to identify factors that were associated with bleeding complications, although multivariable analysis was not performed based on the small sample size. Differences were considered statistically significant at twosided $p$-values of $\leq 0.05$. All analyses were performed using SPSS software (version 25; IBM Corp., Armonk, NY).

\section{Results}

During the study period, 60 patients received Impella ${ }^{\circledR}$ RP devices $(n=20)$ or Impella ${ }^{\circledR} C P / 5.0$ devices ( $n$ = 40) (Fig. 1, Table 1). Detailed coagulation analysis had been performed for 41 patients (Figs. 2-5), although 1 patient was excluded because of device dislocation and an immediate switch to ECMO. Thirty- 
two patients (53.3\%) patients experienced severe or major bleeding events (BARC score of $\geq 3$ ) during treatment (Table 2). Of those 41 patients 28 had bleeding complications.. Additional ECMO was provided for 5 of 20 patients (25\%) who received Impella ${ }^{\circledR}$ RP devices and for 17 of 40 patients (42.3\%) who received Impella ${ }^{\circledR} \mathrm{CP} / 5.0$ devices. There was no significant difference in bleeding complications between patients who did and did not receive ECMO $(p=0.49)$. 
Table 1

Patient characteristics according to Impella $\AA$ use.

\begin{tabular}{|c|c|c|c|c|}
\hline & $\begin{array}{l}\text { All } \\
n=60\end{array}$ & $\begin{array}{l}\text { LV Impella }{ }^{\circledR} \\
\mathrm{n}=\mathbf{4 0}\end{array}$ & $\begin{array}{l}\text { RV Impella }{ }^{\circledR} \\
\mathrm{n}=\mathbf{2 0}\end{array}$ & $\begin{array}{l}p- \\
\text { value }\end{array}$ \\
\hline Age, years & $63(54-70)$ & $68.75(62.0-75.7)$ & $67.0(56.25-76.75)$ & 0.20 \\
\hline $\begin{array}{l}\text { Impella }{ }_{\text {days }} \text { duration, } \\
\text { lat }\end{array}$ & $3.3(1.15-7.85)$ & $5.0(1.15-9.4)$ & $2.55(1.12-7.22)$ & 0.47 \\
\hline ECMO, n (\%) & $22(36.7)$ & $17(42.5)$ & $5(22.5)$ & 0.25 \\
\hline Major bleeding, n (\%) & $32(53.3)$ & $23(57.5)$ & $9(45.0)$ & 0.41 \\
\hline $\begin{array}{l}\text { Access site bleeding, } n \\
(\%)\end{array}$ & $1(1,7 \%)$ & $1(2,5)$ & $0(0)$ & 1.00 \\
\hline avWS, n (\%) & $31(75.6)$ & $21(87.5)$ & $10(58.8)$ & 0.035 \\
\hline Platelets, $\times 10^{9} / \mathrm{L}$ & $117(88-196)$ & $130.0(89.0-242.0)$ & $\begin{array}{l}110.0(88.0- \\
117.75)\end{array}$ & 0.33 \\
\hline $\mathrm{Hb}, \mathrm{g} / \mathrm{dL}$ & $9.6(8.7-10.9)$ & $10.0(9.0-11.8)$ & $9.15(8.52-9.6)$ & 0.016 \\
\hline Fibrinogen, mg/dL & $\begin{array}{l}302.0(224.25- \\
394.5)\end{array}$ & $\begin{array}{l}332.5(242.25- \\
505.0)\end{array}$ & $\begin{array}{l}299.0(187.5- \\
340.75)\end{array}$ & 0.33 \\
\hline Factor II, \% & $63.0(50.0-75.75)$ & $62.5(51.0-75.5)$ & $65.0(39.75-81.25)$ & 0.99 \\
\hline Factor V, \% & $59.0(45.5-75.5)$ & $59.0(48.0-75.5)$ & $58.5(32.75-81.75)$ & 0.82 \\
\hline Factor VII, \% & $53.0(34.0-71.0)$ & $53.0(35.0-61.0)$ & $56.0(31.5-83.0)$ & 0.60 \\
\hline Factor VIII, \% & $\begin{array}{l}356.9(281.7- \\
450.0)\end{array}$ & $\begin{array}{l}356.55(282.52- \\
450.0)\end{array}$ & $\begin{array}{l}450.0(238.8- \\
450.0)\end{array}$ & 0.62 \\
\hline Factor $\mathrm{X}, \%$ & $57.0(47.5-79.0)$ & $57.0(49.0-72.5)$ & $67.0(35.5-95.0)$ & 0.72 \\
\hline Factor XIII, \% & $78.0(65.0-94.0)$ & $83.0(66.0-98.0)$ & $76.5(63.0-87.75)$ & 0.37 \\
\hline AT III, \% & $63.0(54.0-74.0)$ & $63.5(54.25-74.5)$ & $62.0(44.0-74.0)$ & 0.42 \\
\hline yGT, U/L & $\begin{array}{l}45.5(29.25- \\
89.25)\end{array}$ & $70.5(34.5-128.5)$ & $39.5(34.25-57.5)$ & 0.051 \\
\hline ALAT, U/L & $59.0(26.0-166.0)$ & $62.0(27.25-166.0)$ & $56.5(25.0-171.0)$ & 0.65 \\
\hline ASAT, U/L & $\begin{array}{l}131.5(40.75- \\
458.0)\end{array}$ & $142.0(33.25522 .5)$ & $\begin{array}{l}131.5(54.25- \\
352.0)\end{array}$ & 0.83 \\
\hline TCT s & $10.3(9.2-12.57)$ & $10.8(9.42-12.17)$ & $9.9(8.65-14.97)$ & 0.36 \\
\hline aPTT & $35.0(26.0-45.0)$ & $35.4(26.0-44.0)$ & $34.5(26.5-48.75)$ & 0.83 \\
\hline LDH U/I & $\begin{array}{l}616.0(355.0- \\
1472.0)\end{array}$ & $\begin{array}{l}537.0(324.5- \\
1263.0)\end{array}$ & $\begin{array}{l}1282.0(433.75- \\
3209.5)\end{array}$ & 0.081 \\
\hline
\end{tabular}




\begin{tabular}{|c|c|c|c|c|}
\hline & $\begin{array}{l}\text { All } \\
n=60\end{array}$ & $\begin{array}{l}\text { LV Impella }{ }^{\circledR} \\
\mathrm{n}=\mathbf{4 0}\end{array}$ & $\begin{array}{l}\text { RV Impella }{ }^{8} \\
\mathrm{n}=\mathbf{2 0}\end{array}$ & $\begin{array}{l}\mathrm{p}- \\
\text { value }\end{array}$ \\
\hline $\mathrm{RC} n(\%)$ & $8.5(0-22.25)$ & $12.0(0-23)$ & $5(0-12)$ & 0.24 \\
\hline $\mathrm{PC} n(\%)$ & $3(1-6)$ & $2.5(1-6.25)$ & $5(2-6)$ & 0.43 \\
\hline FFP $n(\%)$ & $1(1-2)$ & $5(0-14.5)$ & $6(0-15.0)$ & 0.82 \\
\hline \multicolumn{5}{|c|}{ Data are shown as number (\%) or median (interquartile range). } \\
\hline \multicolumn{5}{|c|}{$\begin{array}{l}\text { ECMO: extra corporal membrane oxygenation; avWS: acquired von Willebrand syndrome; } \mathrm{Hb} \text { : } \\
\text { hemoglobin; ATIII: antithrombin III; 囚GT: } \text {-glutamyl transferase; ALAT: alanine aminotransferase; } \\
\text { ASAT: aspartate aminotransferase; TCT: thrombin clotting time; aPTT: activated partial } \\
\text { thromboplastin time; LDH: lactate dehydrogenase; RC: red cell concentrate; PC: platelet concentrate; } \\
\text { FFP: fresh frozen plasma }\end{array}$} \\
\hline
\end{tabular}


Table 2

Patient characteristics according to bleeding status.

\begin{tabular}{|c|c|c|c|c|}
\hline & All & $\begin{array}{l}\text { Bleeding } \\
(n=32)\end{array}$ & $\begin{array}{l}\text { No bleeding } \\
(n=28)\end{array}$ & $\begin{array}{l}\mathrm{p}- \\
\text { value }\end{array}$ \\
\hline Age, years & $63(54-75)$ & $66(55.75-71)$ & $58.5(46.5-67.5)$ & 0.096 \\
\hline $\mathrm{Hb}, \mathrm{g} / \mathrm{dL}$ & $9.6(8.7-10.9)$ & $9.8(9.0-11.47)$ & $9.3(8.5-10.9)$ & 0.32 \\
\hline Platelets, $\times 10^{9} / \mathrm{L}$ & $\begin{array}{l}117.0(88.0- \\
196.0)\end{array}$ & $110(90-182.25)$ & $130(88-242)$ & 0.63 \\
\hline 囚GT, U/L & $\begin{array}{l}45.5(29.25- \\
89.25)\end{array}$ & $47.5(34.5-95.25)$ & $\begin{array}{l}40.5(21.25- \\
87.25)\end{array}$ & 0.29 \\
\hline ALAT, U/L & $\begin{array}{l}59.0(29.25- \\
89.25)\end{array}$ & $\begin{array}{l}69.0(25.25- \\
166.0)\end{array}$ & $\begin{array}{l}58.5(26.25- \\
271.0)\end{array}$ & 0.79 \\
\hline \multirow[t]{2}{*}{ ASAT, U/L } & 131.5 & 102.0 & 223.5 & 0.34 \\
\hline & $(40.75)$ & $(32.25-388.0)$ & $(55.25-585.75)$ & \\
\hline \multirow[t]{2}{*}{$\mathrm{LDH}, \mathrm{U} / \mathrm{L}$} & 616.0 & 618 & 590 & 0.85 \\
\hline & $(355.0-1,472.0)$ & $(331.0-2,382.0)$ & $\begin{array}{l}(363.25- \\
1,321.25)\end{array}$ & \\
\hline avWS, n (\%) & $31(75.6)$ & $26(92.9)$ & $5(38.5)$ & $\dot{0} 001$ \\
\hline Uncontrolled, n (\%) & $19(31.7)$ & $4(12.5)$ & $15(53.6)$ & 0.001 \\
\hline RC, n (\%) & $8.5(0-22.25)$ & $17.0(4.25-23.75)$ & $2.5(0-11.0)$ & 0.005 \\
\hline PC, n (\%) & $3(1-6)$ & $4(2-8.5)$ & $2(0.5-5.0)$ & 0.056 \\
\hline FFP, n (\%) & $5.5(0-14.5)$ & $6(3-20.5)$ & $0(0-10)$ & 0.063 \\
\hline ECMO, n (\%) & $22(36.7)$ & $13(40.6)$ & $9(32.1)$ & 0.49 \\
\hline $\begin{array}{l}\text { Access site bleeding, } n \\
(\%)\end{array}$ & $1(1.7)$ & $1(3.1)$ & $0(0)$ & 1.0 \\
\hline \multicolumn{5}{|c|}{ Data are presented as number (\%) or median (interquartile range). } \\
\hline \multicolumn{5}{|c|}{$\begin{array}{l}\text { yGT: y-glutamyl transferase; alanine aminotransferase; ASAT: aspartate aminotransferase; LDH: } \\
\text { lactate dehydrogenase; avWS: acquired von Willebrand syndrome; Uncontrolled: missing extensive } \\
\text { analyses; RC: red cell concentrate; PC: platelet concentrate; FFP: fresh frozen plasma; ECMO: extra } \\
\text { corporal membrane oxygenation }\end{array}$} \\
\hline
\end{tabular}

We identified avWS in 31 patients, which was associated with bleeding complications (BARC score of $\geq$ 3) (odds ratio [OR]: $20.8,95 \%$ confidence interval [CI]: 3.36-128.53; $p=0.001$ ). Patients with right-side Impella ${ }^{\circledR}$ RP devices were significantly less likely to develop avWS, relative to patients who received leftside Impella ${ }^{\circledR} \mathrm{CP} / 5.0$ devices (10/17 patients [53.5\%] vs. 21/24 patients [87.5\%]; $p=0.035$ ). Furthermore, bleeding complications were associated with each additional day of treatment (OR: 1.3, 95\% Cl: 1.09- 
$1.55 ; p=0.003$ ) (Tables 3 ). However, the PTT values were not associated with bleeding complications in our cohort. No access site bleeding was observed in the Impella ${ }^{\circledR}$ RP group, although 1 patient $(2.5 \%)$ in the Impella ${ }^{\circledR} \mathrm{CP} / 5.0$ group experienced access site bleeding. No thrombotic complications were observed in any group.

Table 3

Univariate regression analysis of bleeding risk.

\begin{tabular}{|llcc|}
\hline & Odds ratio & $95 \% \mathrm{Cl}$ & p-value \\
\hline avWS & 20.8 & $3.36-128.53$ & 0.001 \\
\hline Impella ${ }^{\circ}$ duration & 1.3 & $1.09-1.55$ & 0.003 \\
\hline aPTT at onset of bleeding & 1.0 & $0.98-1.02$ & 0.98 \\
\hline Variable & Odds ratio & $95 \%$ Cl & p-value \\
\hline avWS & 14.78 & $2.14-101.94$ & 0.006 \\
\hline Impella® duration & 1.07 & $0.89-1.28$ & 0.44 \\
\hline Cl: confidence interval; avWS: acquired von-Willebrand-Syndrome & \\
\hline
\end{tabular}

\section{Discussion}

This study revealed that patients who received Impella ${ }^{\circledR}$ RP devices were less likely to develop avWS during their treatment, relative to patients who received Impella ${ }^{\circledR}$ 5.0/CP devices. Furthermore, the development of avWS was associated with bleeding complications in our cohort. Moreover, we did not identify any cases of thrombotic complications or access site bleeding in the Impella ${ }^{\circledR}$ RP group. The combination of ECMO and Impella ${ }^{\circledR}$ therpy was not associated with a higher incidence of bleeding complications nor with the development of avWS.

Cases of avWS are relatively common after MCS therapy, with reported incidences of $30-100 \%$ depending on the type of support, device, and measurement method. $8,9,14,15$ Furthermore, avWS is associated with an increased risk of bleeding among patients who require MCS. 8, 9, 13, 18, 19, 26 In patients with left ventricular assist devices, avWS is associated with increased risks of early and long-term bleeding complications. ${ }^{8,14}$ In patients who require temporary MSC, such as ECMO, avWS is also very common and is associated with an increased risk of major bleeding complications. ${ }^{11,12,15}$ The severity of the bleeding complications depends on comorbidities, the duration of MCS, and anticoagulation or platelet inhibition during MCS. ${ }^{27}$

This study revealed that the patients had elevated baseline values for vWF:Ag and vWF:Ac, with a normal activity-to-antigen ratio. Although none of the patients fulfilled the diagnostic criteria for possible avWS preoperatively, many exhibited reduced vWF function that was reflected in a reduced activity-to-antigen ratio. In this context, avWS is caused by the loss of large vWF multimers via increased vWF clearance, 
increased binding to cell surfaces, and/or proteolytic loss. During MCS, avWS is predominantly related to increased proteolytic cleavage of VWF by ADAMTS13, which is promoted by shear stress-dependent conformational changes in these multimers. This cleavage increases the risk of bleeding among patients who require MCS. In our cohort, despite similar pump power and support, avWS was less common in the group that received right ventricular support (vs. left ventricular support), which might be related to lower pressures and less shear stress at the right ventricular site. Another possible explanation is that the group that received left ventricular support was more likely to receive both ECMO and an Impella ${ }^{\circledR}$ device, which would suggest that two MCS strategies could increase the risk of avWS. However, we failed to detect a significant difference in avWS or major bleeding complications according to the use or non-use of ECMO.

Bleeding complications after Impella ${ }^{\circledR} \mathrm{CP} / 5.0$ device implantation may compromise the outcomes in patients with cardiogenic shock. ${ }^{6,21}$ In particular, access site complications have been discussed as potential causes of major bleeding. Unfortunately, previous studies have provided limited information regarding anticoagulation strategies, bleeding locations, and temporal relationships with Impella® device implantation. Therefore, further studies are needed to address these issues.

The Impella ${ }^{\circledR}$ RP device is a novel mechanical right ventricular support system. However, given the relatively uncommon nature of isolated acute right ventricular failure, there is limited experience with Impella ${ }^{\circledR}$ RP devices and most centers have performed $<10$ implantations. Thus, given their early locations on the learning curve, most centers have been unable to provide useful data regarding access site bleeding and major bleeding complications in cases with Impella ${ }^{\circledR}$ RP usage. To the best of our knowledge, our experience with 20 patients who received Impella® RP devices is the largest single-center cohort at this time. We did not detect any right ventricular support cases with access site complications, which may be related to venous access being safe, based on the lower pressure and less calcification. Given the short learning curve, safe implantation for right and left ventricular support seems possible. Thus, while access site management might contribute to bleeding complications, it did not play a major role in our cohort.

We still observed a significant number of major and fatal bleeding events in our cohort (32 patients, 53\%). This may be related to the use of these devices as a last resort in patients who were failing previous treatment, especially early in our learning curve, which might suggests that the patients had severe cardiogenic shock with or without right ventricular failure. Furthermore, after the first implantations, we used PTT and activated clotting time to control anticoagulation, while laboratory testing for other coagulation factors, such as VWF, was only performed for patients with bleeding complications. However, after clinical observation of bleeding complications, we established a standard operating procedure that included testing for coagulation factors and avWS screening. We suggest that anticoagulant management during Impella ${ }^{\circledR}$ treatment should be differentiated beyond simple testing for activated clotting time or PTT.

The present study has various limitations that should be considered. First, the retrospective analysis of data regarding avWS and bleeding events inherently selects for patients who underwent related testing,

Page $11 / 19$ 
although this was not routinely performed during the first few months after this novel treatment was established. Thus, the results might be influenced by selection bias and a prospective study is needed to confirm the incidence of avWS during Impella ${ }^{\circledR}$ treatment and its association with bleeding complications. Second, the analysis of VWF parameters was limited to VWF:Ag and vWF:Ac, which precludes a commentary regarding VWF multimers and the potential influences of ADAMTS13 on vWF parameters. Furthermore, it can be difficult to evaluate the VWF activity-to-antigen ratio in a situation with highly elevated vWF parameters, although certain patients with avWS-associated disorders may only exhibit reduced concentrations of high molecular weight vWF multimers during laboratory testing. Third, a large subgroup of patients was receiving preprocedural antiplatelet and anticoagulation therapy, which suggests that alternative causes of bleeding complications are possible. Fourth, the shear stress induced by centrifugal pumps depends on the rotational speed, and pump designs with different flow patterns may have different effects on coagulation parameters. Further studies of these differences are needed to guide optimal anticoagulation management in this setting.

Based on the association between aVWS and bleeding complication observes in this study, we updated our diagnostic strategy for all patients who require axial flow pump support to routinely include testing for factors II, V, VII, VIII, X, and XIII, as well as antithrombin III, thrombin clotting time, aPTT, international normalized ratio, and vWF:Ac. Furthermore, all patients who require MCS are screened for avWS before implantation, as well as factor deficiencies and avWS on days 1,3, and 5. In cases with major bleeding and avWS, we administer factor VIII and VWF (Haemate $\AA$ ) to achieve a platelet count of $>100,000 / \mathrm{mL}$ and normalize the aPTT. In cases with avWS but no bleeding, we aim for lower PTT values (35-40 s) and a platelet count of $>70,000 / \mathrm{mL}$. We plan to evaluate the possible benefits of this more differentiated anticoagulation strategy in a prospective study.

\section{References}

1. Pesarini, G., Gratta, A., Dolci, G., Lunardi, M. \& Ribichini, F. L. Impella-protected PCl: the clinical results achieved so far. Minerva Cardioangiol, 66, 612-618 (2018).

2. Anderson, M. B. et al. Benefits of a novel percutaneous ventricular assist device for right heart failure: The prospective RECOVER RIGHT study of the Impella RP device. The Journal of heart and lung transplantation: the official publication of the International Society for Heart Transplantation, 34, 1549-1560 (2015).

3. Dalal, P. K., Mertens, A., Shah, D. \& Hanson, I. Hemodynamic Support Using Percutaneous Transfemoral Impella 5.0 and Impella RP for Refractory Cardiogenic Shock. Case Rep Cardiol, 2019, 4591250 (2019).

4. Jensen, P. B. et al. Single-centre experience with the Impella CP, 5.0 and RP in 109 consecutive patients with profound cardiogenic shock. Eur Heart J Acute Cardiovasc Care, 7, 53-61 (2018).

5. Pappalardo, F. et al. Concomitant implantation of Impella((R)) on top of veno-arterial extracorporeal membrane oxygenation may improve survival of patients with cardiogenic shock. European journal of heart failure, 19, 404-412 (2017). 
6. Amin, A. P. et al. The Evolving Landscape of Impella Use in the United States Among Patients Undergoing Percutaneous Coronary Intervention With Mechanical Circulatory Support., 141, 273-284 (2020).

7. Schrage, B. et al. Schafer A and Westermann D. Impella Support for Acute Myocardial Infarction Complicated by Cardiogenic Shock., 139, 1249-1258 (2019).

8. Bansal, A. et al. Effects of a fully magnetically levitated centrifugal-flow or axial-flow left ventricular assist device on von Willebrand factor: A prospective multicenter clinical trial. The Journal of heart and lung transplantation: the official publication of the International Society for Heart Transplantation, 38, 806-816 (2019).

9. Berger, J., Schwartz, J., Ramachandran, S. \& Leff, J. D. Review of von Willebrand Disease and Acquired von Willebrand Syndrome for Patients Undergoing Cardiac Surgery. Journal of cardiothoracic and vascular anesthesia, 33, 3446-3457 (2019).

10. Davis, M. E., Haglund, N. A., Tricarico, N. M., Keebler, M. E. \& Maltais, S. Development of acquired von Willebrand syndrome during short-term micro axial pump support: implications for bleeding in a patient bridged to a long-term continuous-flow left ventricular assist device. ASAIO J, 60, 355-357 (2014).

11. Flierl, U. et al. Acquired von Willebrand syndrome in cardiogenic shock patients on mechanical circulatory microaxial pump support. PloS one, 12, e0183193 (2017).

12. Goldfarb, M. et al. High Molecular Weight von Willebrand Factor Multimer Loss and Bleeding in Patients with Short-Term Mechanical Circulatory Support Devices: A Case Series. J Extra Corpor Technol, 50, 77-82 (2018).

13. Meyer, A. L. et al. Acquired von Willebrand syndrome in patients with an axial flow left ventricular assist device. Circulation Heart failure, 3, 675-681 (2010).

14. Rosenberg, G. et al. Acquired Von Willebrand Syndrome and Blood Pump Design. Artif Organs, 42, 1119-1124 (2018).

15. Uriel, N. et al. Acquired von Willebrand syndrome after continuous-flow mechanical device support contributes to a high prevalence of bleeding during long-term support and at the time of transplantation. Journal of the American College of Cardiology, 56, 1207-1213 (2010).

16. Tsai, H. M., Sussman, I. I. \& Nagel, R. L. Shear stress enhances the proteolysis of von Willebrand factor in normal plasma., 83, 2171-2179 (1994).

17. Geisen, U. et al. Non-surgical bleeding in patients with ventricular assist devices could be explained by acquired von Willebrand disease. European journal of cardio-thoracic surgery: official journal of the European Association for Cardio-thoracic Surgery, 33, 679-684 (2008).

18. Tiede, A. et al. Diagnostic workup of patients with acquired von Willebrand syndrome: a retrospective single-centre cohort study. Journal of thrombosis and haemostasis: JTH, 6, 569-576 (2008).

19. Avila, M. L. et al. Acquired von Willebrand syndrome in paediatric patients with congenital heart disease: challenges in the diagnosis and management of this rare condition., 21, e89-92 (2015). 
20. Federici, A. B., Canciani, M. T., Forza, I. \& Cozzi, G. Ristocetin cofactor and collagen binding activities normalized to antigen levels for a rapid diagnosis of type 2 von Willebrand disease-single center comparison of four different assays. Thromb Haemost, 84, 1127-1128 (2000).

21. Laffan, M. et al. The diagnosis of von Willebrand disease: a guideline from the UK Haemophilia Centre Doctors' Organization., 10, 199-217 (2004).

22. Geisen, U. et al. Comparison of Von Willebrand factor (VWF) activity VWF:Ac with VWF ristocetin cofactor activity VWF:RCo. Thromb Res, 134, 246-250 (2014).

23. Heilmann, C. et al. Acquired von Willebrand syndrome in patients with extracorporeal life support (ECLS). Intensive care medicine 2012;38:62 - 8.

24. Stortecky, S. et al. Validation of the Valve Academic Research Consortium Bleeding Definition in Patients With Severe Aortic Stenosis Undergoing Transcatheter Aortic Valve Implantation. J Am Heart Assoc, 4, e002135 (2015).

25. Favaloro, E. J. \& Mohammed, S. Towards improved diagnosis of von Willebrand disease: comparative evaluations of several automated von Willebrand factor antigen and activity assays. Thromb Res, 134, 1292-1300 (2014).

26. Kalbhenn, J. et al. Early diagnosis of acquired von Willebrand Syndrome (AVWS) is elementary for clinical practice in patients treated with ECMO therapy. J Atheroscler Thromb, 22, 265-271 (2015).

27. Geisen, U. et al. Schlagenhauf A and Zieger B. Platelet Secretion Defects and Acquired von Willebrand Syndrome in Patients With Ventricular Assist Devices.J Am Heart Assoc. 2018;7.

\section{Figures}




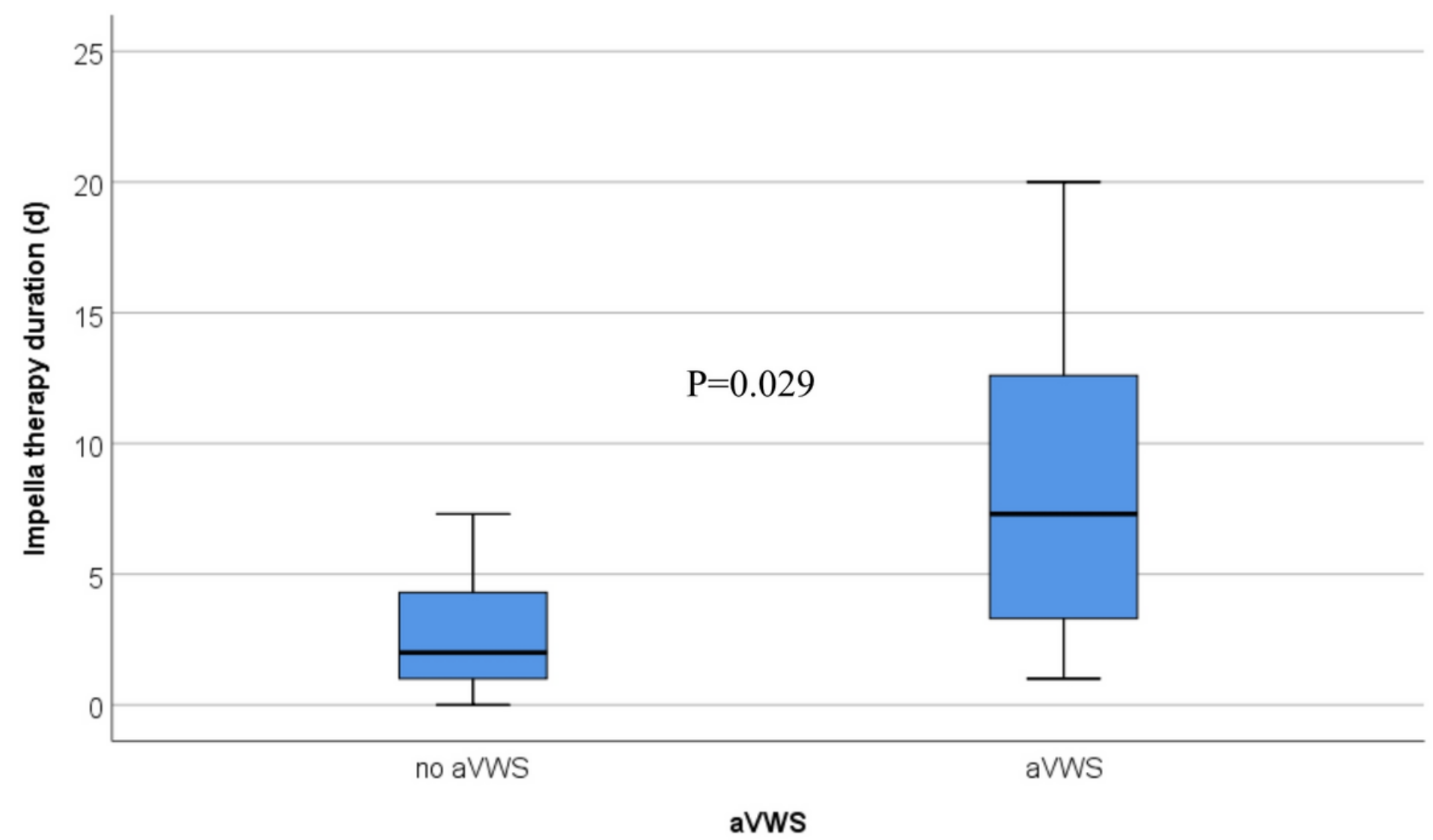

Figure 1

Impella ${ }^{\circledR}$ treatment duration in patients who developed acquired von Willebrand syndrome Legend avWS: acquired von Willebrand syndrome 


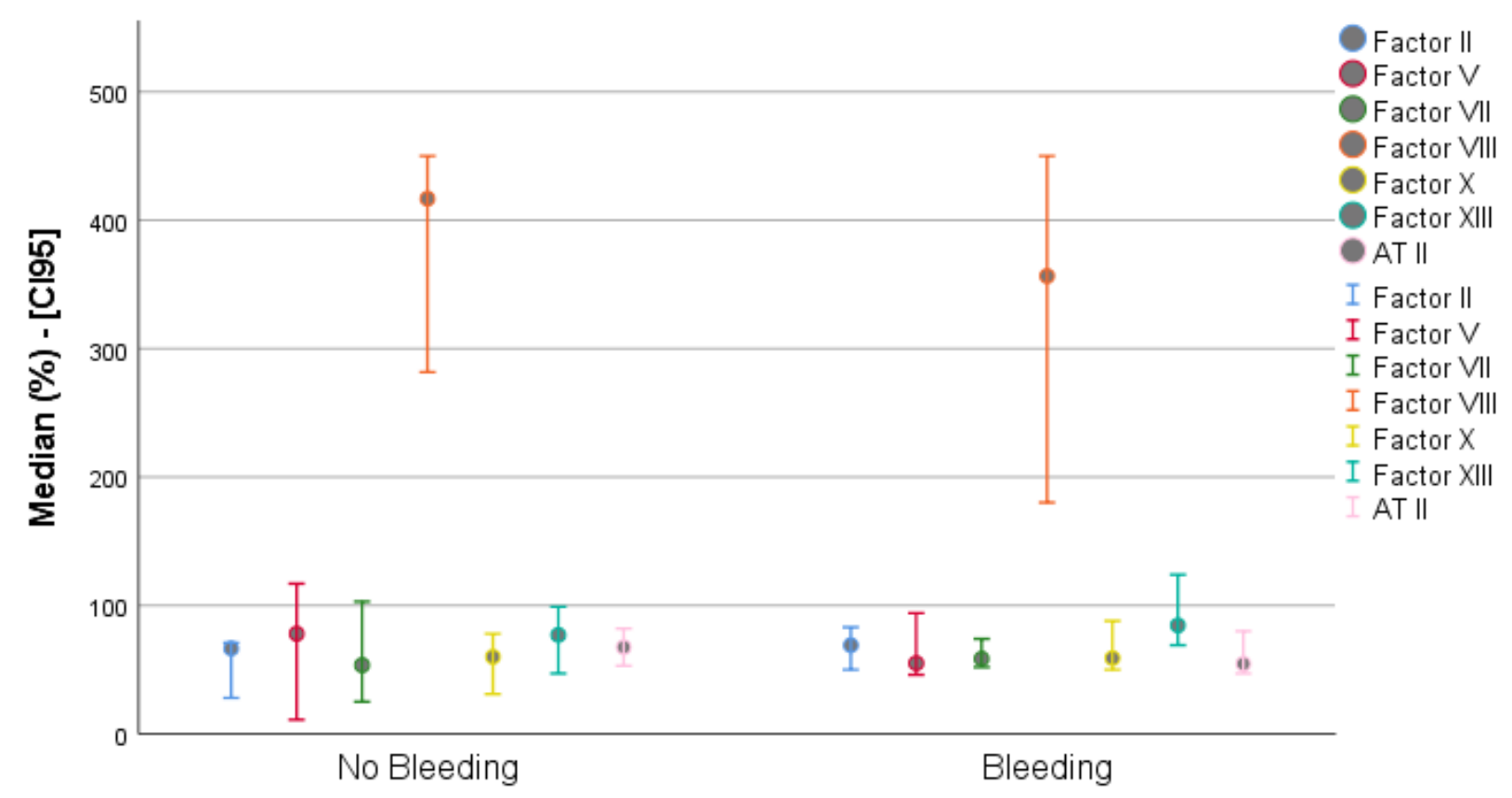

Bleeding $B A R C \geq 3$

Figure 2

Coagulation factors on the day of implantation. Legend: AT III: Antithrombin III; BARC: The Bleeding Academic Research Consortium 


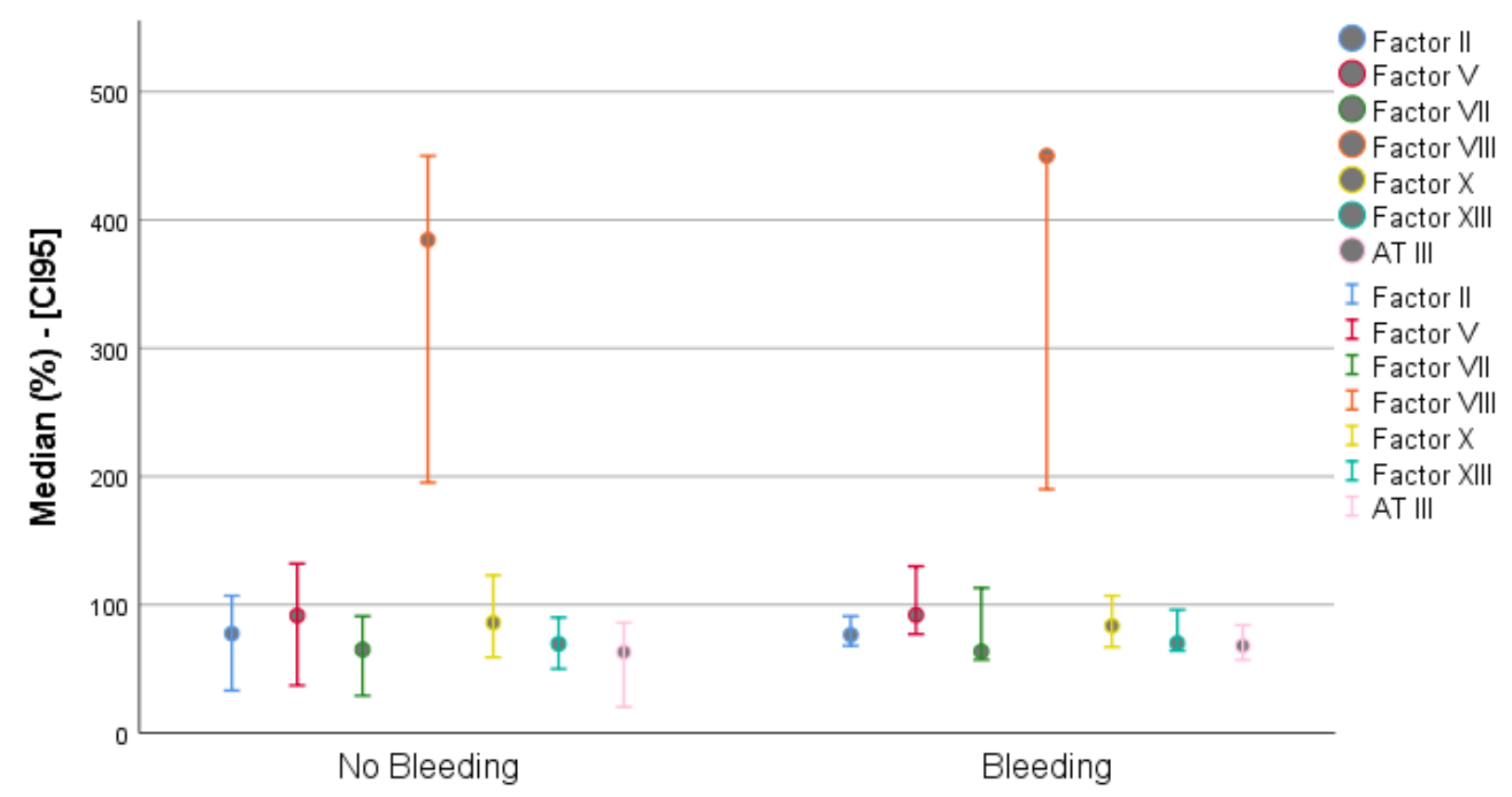

Bleeding BARC $\geq 3$

\section{Figure 3}

Coagulation factors at the onset of bleeding. Legend: AT III: Antithrombin III; BARC: The Bleeding Academic Research Consortium 


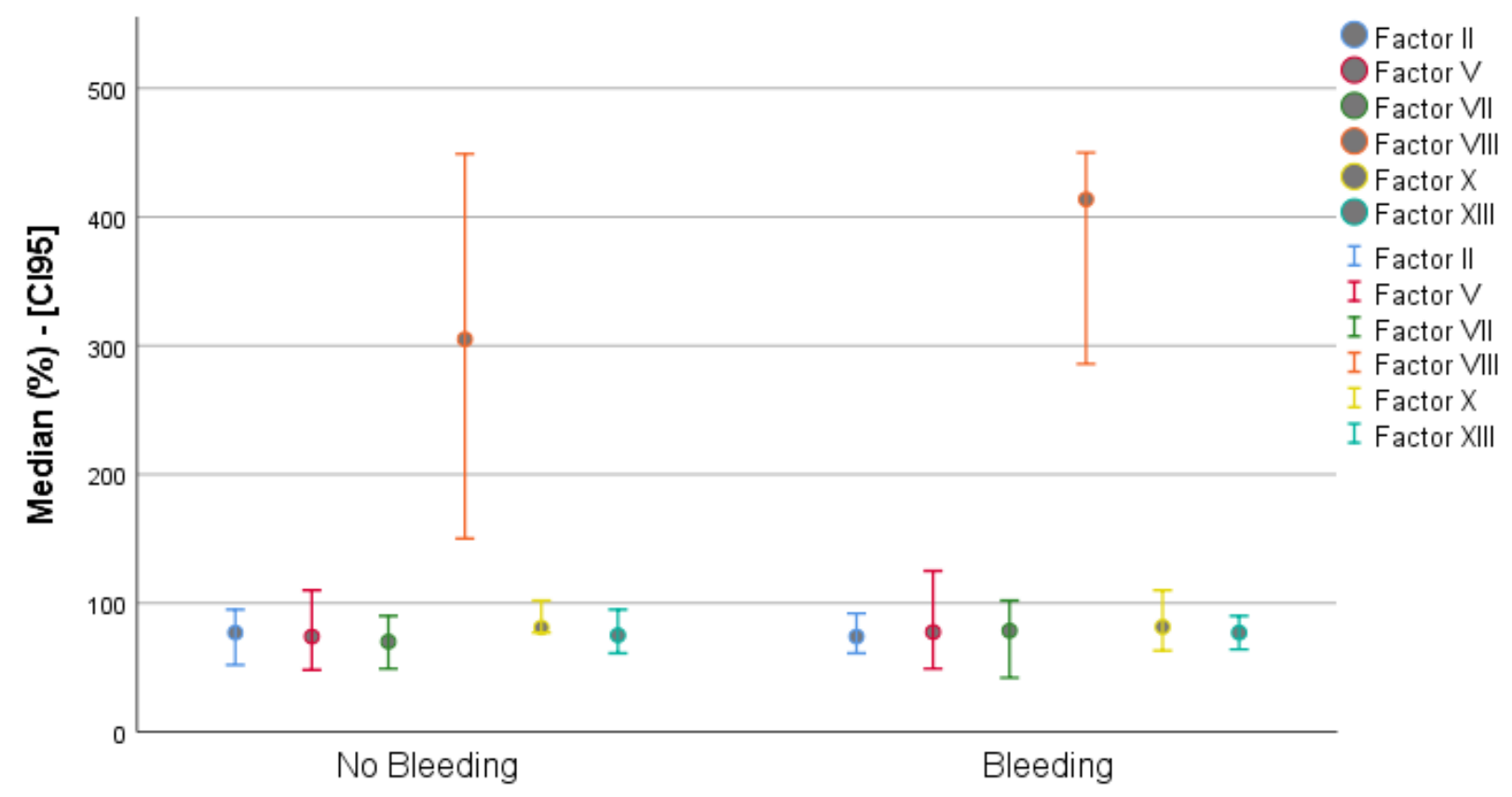

Bleeding $B A R C \geq 3$

\section{Figure 4}

Coagulation factors after explantation. AT III: Antithrombin III; BARC: The Bleeding Academic Research Consortium 


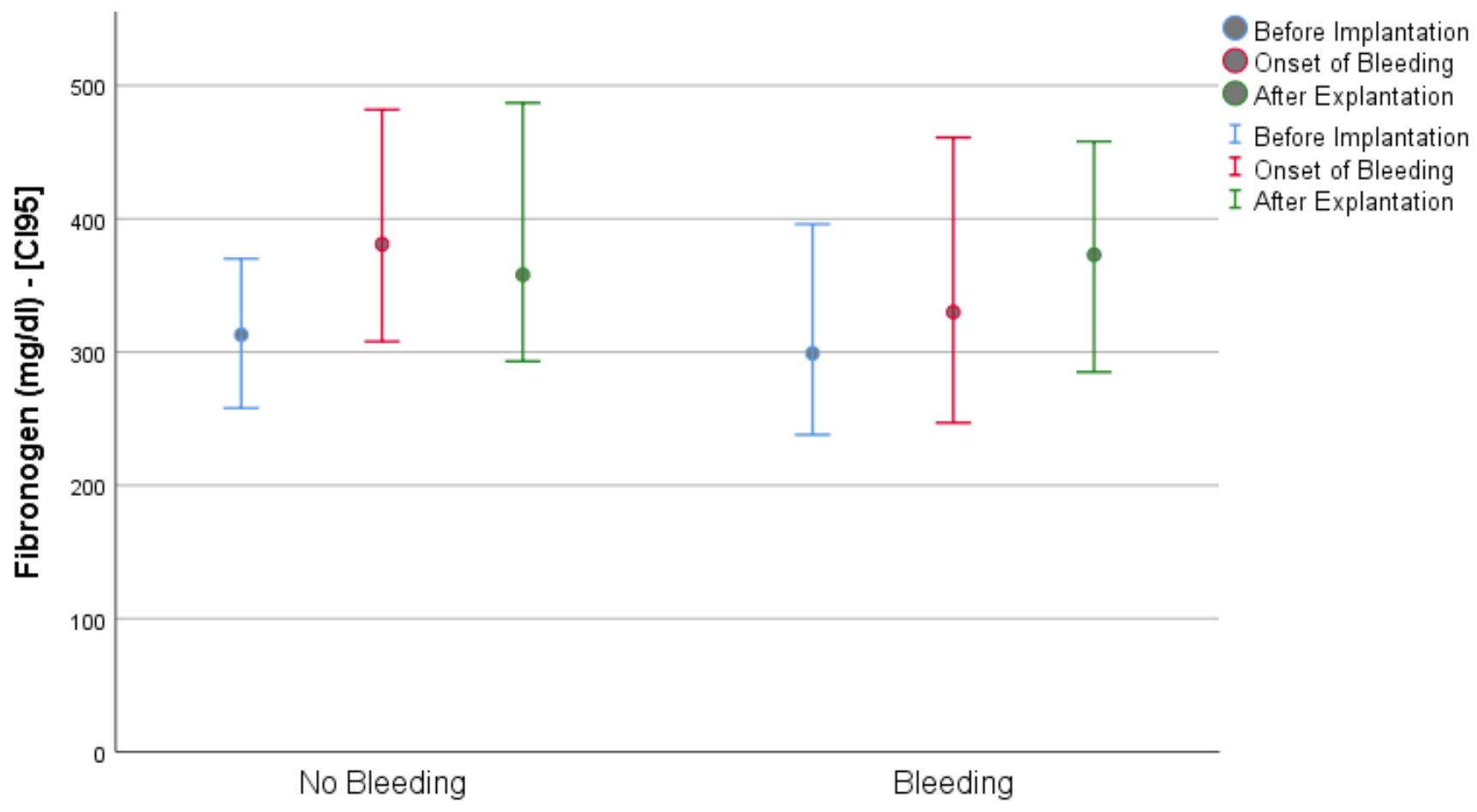

Bleeding $B A R C \geq 3$

Figure 5

Changes in fibrinogen concentrations over time. Legend: BARC: The Bleeding Academic Research Consortium 